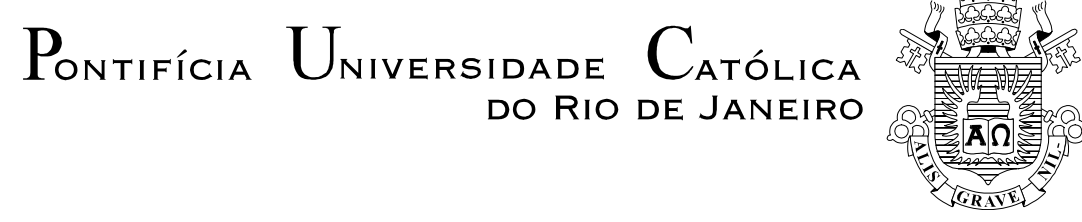

Ricardo Resende

\title{
Percepção e Uso do Telefone Celular entre \\ Consumidores de Mais Idade
}

\section{Dissertação de Mestrado}

Dissertação apresentada ao Programa de Pós-Graduação em Administração de Empresas da PUC-Rio como requisito parcial para obtenção do título de Mestre em Administração de Empresas.

Orientador: Prof. Paulo Cesar de Mendonça Motta

Rio de Janeiro 


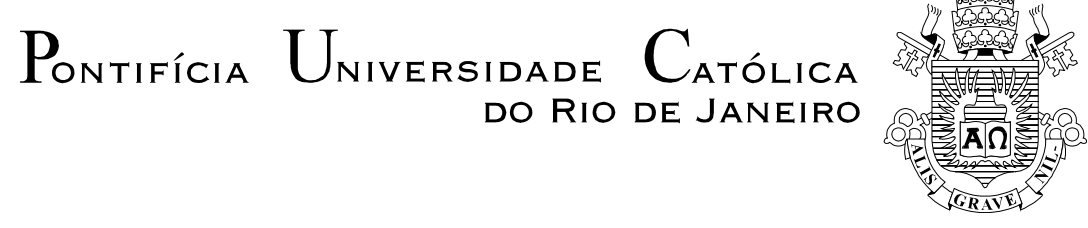

Ricardo Resende

\section{Percepção e Uso do Telefone Celular entre Consumidores de Mais Idade}

Dissertação apresentada como requisito parcial para obtenção do grau de Mestre pelo Programa de Pósgraduação em Administração de Empresas da PUC-Rio. Aprovada pela Comissão Examinadora abaixo assinada.

Prof. Paulo Cesar de Mendonça Motta Orientador Departamento de Administração - PUC-Rio

Prof. Luis Fernando Hor-Meyll Alvares Departamento de Administração - PUC-Rio

Prof $^{a}$. Mônica Zaidan Gomes Rossi FACC - UFRJ

Prof. Nizar Messari Vice-Decano de Pós-Graduação do CCS

Rio de Janeiro, 29 de setembro de 2009 
Todos os direitos reservados. É proibida a reprodução total ou parcial do trabalho sem autorização da universidade, do autor e do orientador.

\section{Ricardo Resende}

É graduado em Engenharia Elétrica-Eletrônica pela UERJ e em Administração pela UFRJ. Tem Pos-Graduação em Engenharia de Produção (UFF), MBA em Marketing (FGV-RJ) e em Gestão Empresarial (PUC-Rio). Trabalha na Petrobras, como engenheiro de telecomunicações e, antes disso, atuou em outras empresas do mercado, como engenheiro de eletrônica.

Ficha Catalográfica

Resende, Ricardo

Percepção e uso do telefone celular entre consumidores de mais idade / Ricardo Resende ; orientador: Paulo Cesar de Mendonça Motta. - 2009.

$107 \mathrm{f} . ; 30 \mathrm{~cm}$

Dissertação (Mestrado em Administração) Pontifícia Universidade Católica do Rio de Janeiro, Rio de Janeiro, 2009.

Inclui bibliografia

1. Administração - Teses. 2. Consumidor de mais idade. 3. Serviço celular. 4. Aparelho celular. 5. Mobilidade. 6. Restrições ao uso. 7. Modelo de restrições. I. Motta, Paulo Cesar de Mendonça. II. Pontifícia Universidade Católica do Rio de Janeiro. Departamento de Administração. III. Título.

CDD: 658 
À minha família - Hustana, Ivan e Stella- sempre presentes.

À minha mãe, “dona” Terezinha, referência e apoio constante.

Ao meu pai, José Pedro, in memoriam. Pena que não mais esteja entre nós. A todos que, a despeito das dificuldades e desafios da vida, não deixam de sonhar e lutar por seus sonhos. 


\section{Agradecimentos}

Agradeço, em primeiríssimo lugar, ao professor Paulo Cesar de Mendonça Motta, pelas valiosas e sempre precisas orientações. Sua experiência como professor, pesquisador e orientador foram fundamentais para a condução desse trabalho.

Agradeço também à minha mulher - Hustana - e meus filhos - Ivan e Stella - pelo encorajamento e estímulo que me deram ao longo do caminho. Não foi pequeno o tempo de convívio familiar que lhes subtraí.

E agradeço muito àqueles que, de uma forma ou outra, a começar dos próprios indivíduos entrevistados, contribuíram para a concretização desse trabalho. O que significa, também, minha gratidão junto àqueles que intermediaram a abordagem junto a alguns dos entrevistados.

Por fim, não posso deixar de agradecer à Deus pela luz e energia a mim concedidas. A conclusão desse trabalho renova a fé que n’Ele tenho e a crença de que, sem Ele e meu Anjo da Guarda, nada sou. 


\section{Resumo}

Resende, Ricardo; Motta, Paulo Cesar de Mendonça. Percepção e Uso do Telefone Celular entre Consumidores de Mais Idade. Rio de Janeiro, 2009. 107p. Dissertação de Mestrado - Departamento de Administração, Pontifícia Universidade Católica do Rio de Janeiro.

Este estudo objetiva capturar a forma com a qual o consumidor mais velho percebe e utiliza o serviço de telefonia celular e o aparelho em si. O trabalho objetiva também propor um modelo de explicite a forma e as restrições ou barreiras que têm esses consumidores ao uso mais pleno do serviço celular. Através de uma abordagem qualitativa, foram realizadas entrevistas com consumidores com idade superior a 50 anos. As entrevistas foram gravadas e transcritas para análise. Os resultados mostram as especificidades de uso entre os consumidores de mais idade, particularmente a baixa percepção dos dispositivos como um artefato multifunção, com potencial para auxiliá-los em muitas tarefas de seus respectivos cotidianos, através das múltiplas funcionalidades que incorpora. O estudo propõe um modelo que explicita a existência de dimensões distintas de restrições, onde cada dimensão dá conta de um conjunto específico de barreiras ao pleno uso da telefonia e do telefone celular.

\section{Palavras-chave}

Consumidor de mais idade; serviço celular; aparelho celular; mobilidade; restrições ao uso; modelo de restrições. 


\section{Abstract}

Resende, Ricardo; Motta, Paulo Cesar de Mendonça (Advisor). Perception and Use of Cellular Phone for Older Consumers. Rio de Janeiro, 2009. 107p. MSc Dissertation - Departamento de Administração, Pontifícia Universidade Católica do Rio de Janeiro.

This study targets to capture the way in wich the older consumer (age 50+) perceives and uses the mobile cellular service and the celular phone as well. That work also proposes an model that reveals the way and constraints or barriers these consumers have to full use of mobile cellular service. By using an qualitative approach, some interviews was done with older consumers. The interviews was recorded and transcripted for analisys. The results show the specificities of use for those consumers, notably the low perception they have regarding the phones as an multifunction devices with potential to help them in many tasks of their lives. The work also proposes an model that show the presence of multiple dimensions of constraints to cellular phone and service use. Each constraint reveiling an specific set of barriers to full use of telephony and cellular phone.

\section{Keywords}

Older consumers; cellular service; cellular phone; mobility; use constraints; constraints model. 


\section{Sumário}

1. Introdução 11

1.1. Motivação 11

1.2. O Problema 19

1.3. Objetivos do Trabalho $\quad 24$

1.4. Relevância do Estudo $\quad 26$

1.5. Delimitação do Estudo 28

2. O Setor de Telefonia Celular 29

2.1. Histórico 29

2.2. O mercado brasileiro de telefonia celular 30

2.3. O serviço celular no Estado do Rio de Janeiro 36

3. Revisão da Literatura 38

3.1. O Consumidor Mais Velho 38

3.2. Os Efeitos Idade, Coortes e Período $\quad 40$

3.3. As Experiências de Vida, as Mudanças de Papéis e a Função do
Estresse e de seu Enfrentamento no Comportamento de Consumo

3.4. Consumidor em Desvantagem $\quad 50$

3.5. Modelo de Restrições ao Consumo 60

3.6. Síntese da literatura 65

4. O Método $\quad 68$

4.1. Tipo de Pesquisa 68

4.2. Etapas da Pesquisa $\quad 68$

4.3. Procedimentos utilizados

5. Resultados 73

5.1. Sinopse das Transcrições e Análise Categorial 73

5.2. Percepção sobre o aparelho celular 73

5.3. Percepção sobre os acessórios do aparelho celular 76

5.4. O uso dado às funcionalidades do aparelho celular 77

5.5. Percepção sobre o serviço de comunicação móvel celular e de

5.6. Percepção sobre serviços de suporte ou apoio $\quad 84$

5.7. Percepção sobre Operadoras e Outros Atores do Processo 85

5.8. Percepção sobre contribuições do celular ao cotidiano 88

5.9. Percepção de valor do serviço e dos custos envolvidos 90

5.10. Percepção das próprias dificuldades que tem o entrevistado 92

6. Conclusões, Recomendações e Sugestões de Estudos 95

6.1. Conclusões 95

6.2. Recomendações 103

6.3. Sugestões para trabalhos futuros 104

$\begin{array}{ll}\text { 7. Referências bibliográficas } & 106\end{array}$ 


\section{Lista de figuras}

Figura 1: Projeção de crescimento da proporção da população de 60 anos ou mais de idade, segundo o sexo - Brasil - 2000-2020

Figura 2: Proporção de pessoas de 60 anos ou mais de idade em relação aos demais, em países selecionados - 1990/1999

Figura 3: Página internet da empresa Emporia Telecom anunciando novos aparelhos celulares, especialmente desenhados para o público idoso

Figura 4 : Proporção da população residente de 60 anos ou mais de idade, segundo os Municípios das Capitais da Federação

Figura 5:Evolução anual, de 2000 a 2009, da quantidade de linhas (acessos) celulares.

Figura 6: Áreas de Concessão definidas pela ANATEL em 1997. Subdivisão geográfica de exploração de serviço celular

Figura 7: Mapa representativo da competição entre prestadoras do serviço celular no Brasil

Figura 8: Dinâmica dos efeitos idade, coorte e período

Figura 9: Efeito de dois períodos a influenciar um indivíduo

Figura 10: Estrutura para determinação de desvantagem do consumidor

Figura 11: Estrutura de determinação de desvantagem de um consumidor mais velho na compra de um aparelho celular

Figura 12: Modelo de restrição ao consumo de lazer, de Godbey e Crawford.

Figura 13: Modelo aprimorado de restrição ao consumo de lazer.

Figura 14: Modelo de restrições ao lazer, incorporando as restrições culturais

Figura 15: Modelo de restrições ao uso da telefonia celular pelos consumidores de mais idade 


\section{Lista de quadros}

Quadro 1: População brasileira segundo os grupos de idade - Brasil - 2008

Quadro 2: Distribuição das pessoas de 10 anos ou mais de idade, que tinham telefone móvel celular, para uso pessoal, por Grandes Regiões, segundo grupos de idade - 2005

Quadro 3: Regiões/Cidades com maiores índices de teledensidade do país

Quadro 4: Matéria ANATEL sobre rompimento de 100\% de teledensidade

Quadro 5: Principais mercados mundiais de serviço celular

Quadro 6: Operadoras regionais do serviço celular constituídas ao final dos anos 90

Quadro 7: Distribuição das Operadoras Estatais por Área de Concessão

Quadro 8: Distribuição de Celulares pelo território brasileiro em dezembro de 2009

Quadro 9: Participação de mercado das operadoras do serviço celular no Estado do Rio de Janeiro

Quadro 10: Consumo médio (por celular) de SMS no mundo

Quadro 11: Consumidores entrevistados 